\title{
A case of blowout fracture of the orbital floor in early childhood
}

This article was published in the following Dove Press journal:

International Medical Case Reports Journal

27 July 2015

Number of times this article has been viewed

\author{
Akira Sugamata \\ Naoki Yoshizawa \\ Department of Plastic and \\ Reconstructive Surgery, Tokyo \\ Medical University Hachioji \\ Medical Center, Tokyo, Japan
}

Correspondence: Akira Sugamata Department of Plastic and Reconstructive Surgery, Tokyo Medical University Hachioji Medical Center, Tatemachi II63, Hachioji City, Tokyo 193-0998, Japan

Tel +8I 4266556 I I

Fax $+8 I 426651796$

Email sugamata@tokyo-med.ac.jp
Abstract: There are few reports of blowout fractures of the orbital floor in children younger than 5 years of age; in a search of the literature, we found only six reported cases which revealed the exact age, correct diagnosis, and treatment. We herein report the case of a 3-year-old boy with a blowout fracture of the orbital floor. Computed tomography showed a pure blowout fracture of the left orbital floor with a slight dislocation of the orbital contents. The patient was treated conservatively due to the absence of abnormal limitation of eye movement or enophthalmos. The patient did not develop any complications that necessitated later surgical intervention. Computed tomography at 6 months after the injury showed the regeneration of the orbital floor in the area of the fracture and no abnormalities in the left maxillary sinus. We herein present our case and the details of six other cases reported in the literature, and discuss their etiology, diagnosis, and treatment methods.

Keywords: blowout fracture, orbital fracture, pediatric blowout fracture

\section{Introduction}

Blowout fractures of the orbital floor are a frequent occurrence in adults, and the mechanisms of injuries, clinical presentations, and indications for treatment have been well described by numerous authors. However, there are few reports relating to blowout fractures of the orbital floor in children younger than 5 years of age. A search of the PubMed database using the term, "pediatric blowout fractures or blowout fractures in children", revealed only six reports, in which the exact age, correct diagnosis, and treatment were noted. ${ }^{1-5}$ We experienced the case of a 3-year-old boy with a blowout fracture of the orbital floor. We herein present our case, along with the detailed information of six other cases that were reported in the literature, and discuss their etiology, diagnosis, and treatment methods.

\section{Case report}

A boy of 3 years and 3 months of age was reported to have fallen from the front child seat of a bicycle. The boy's mother reported no history of loss of consciousness or vomiting. The boy was taken to the neurosurgery section of a local hospital. A computed tomography (CT) scan was performed at the local hospital and showed a pure blowout fracture of the left orbital floor with a slight dislocation of the orbital contents. No brain abnormalities were observed. He was referred by the local hospital with an indication for surgery to repair his blowout fracture on the same day. A facial examination revealed no abnormalities with the exception of a small subcutaneous ecchymosis in the left lower eyelid. A medical examination revealed that there was no abnormal limitation 
of eye movement or enophthalmos (Figure 1). A fundoscopy also revealed no abnormal findings in the vitreous body or the retina. Due to the lack of clinical symptoms, we selected the conservative option of observation without surgery. The patient did not develop any complications that necessitated later surgical intervention.

CT at 6 months after the injury showed the regeneration of the orbital floor in the area of the fracture and no abnormal findings in the left maxillary sinus (Figure 2).

\section{Discussion}

Blowout fractures of the orbital floor in early childhood have usually been reported either with other pediatric maxillofacial injuries, or in a series of injuries which include adults. ${ }^{6-10}$ In our search of the literature, the youngest reported patient that we could find was 11 months of age. ${ }^{6}$ However, there have been few detailed case reports of blowout fractures of the orbital floor in children younger than 5 years of age. In this age period, the upper third of the developing face is more prominent and is more frequently exposed to injuries than the malar bone. Consequently, orbital roof fractures are more frequently encountered than orbital floor fractures. ${ }^{11,12}$ In our

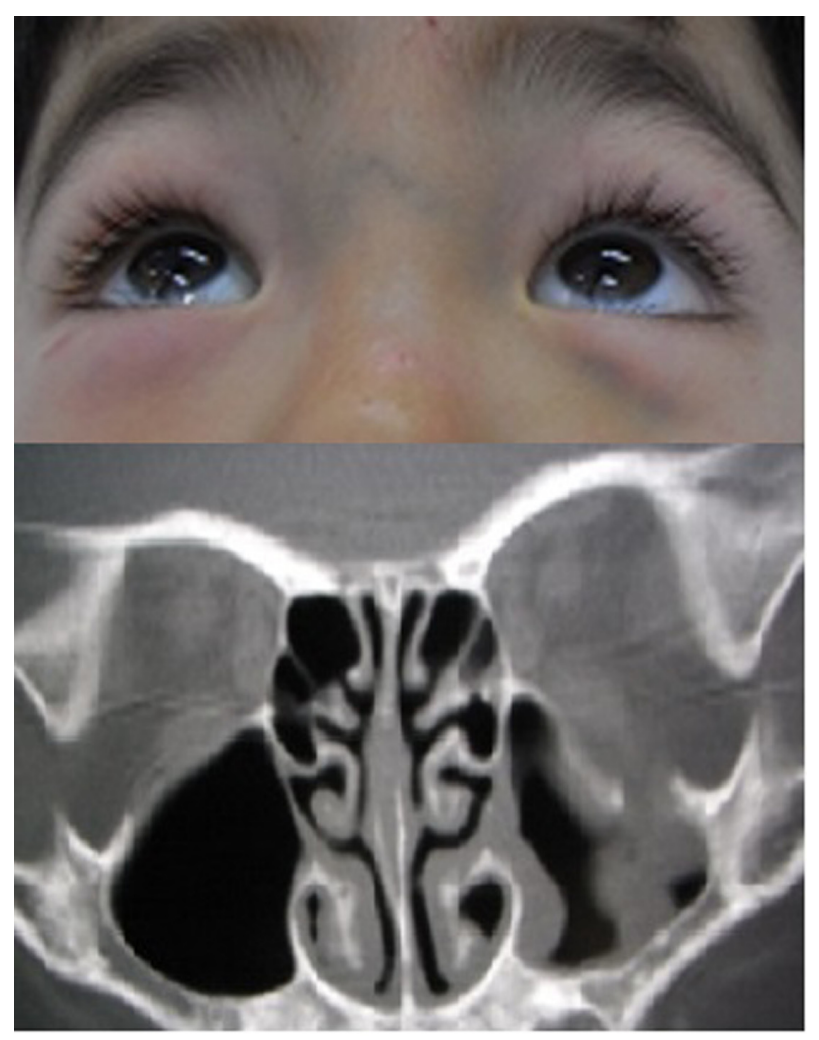

Figure I Computed tomography of a boy of 3 years and 3 months of age showing a pure blowout fracture of the left orbital floor with a slight dislocation of orbital contents.

Note: There was no abnormality in his ocular movement.

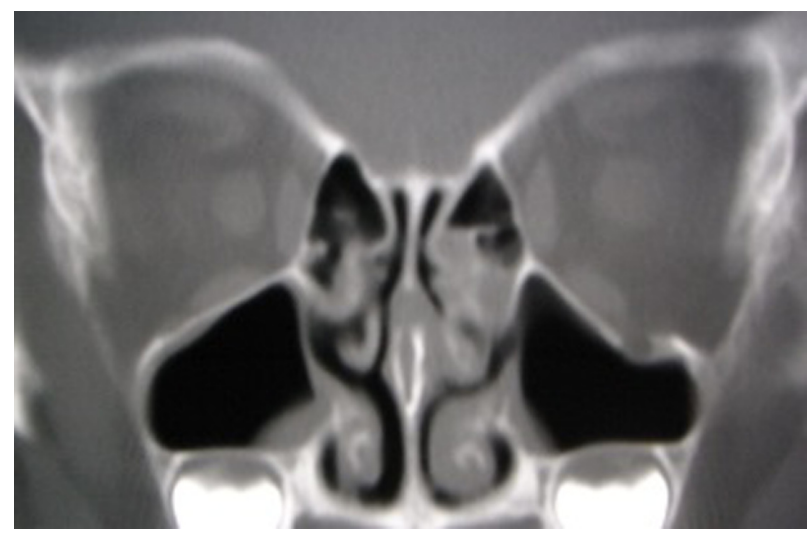

Figure 2 Computed tomography 6 months after the injury shows the regeneration of the left orbital floor and no abnormalities in the left maxillary sinus.

search of the literature, we could only find six case reports of blowout fractures of the orbital floor that mentioned the diagnosis, treatment, and results (Table 1$).{ }^{1-5}$

Three principal mechanisms have been proposed to explain the etiology of blowout fractures: globe-to-wall contact, hydraulic, and the buckling mechanism. ${ }^{13}$ Pediatric patients, especially in early childhood, are most susceptible to the buckling mechanism due to a direct strike to the orbital rim. ${ }^{14}$ The bones of children tend to bend, crack, and then snap back into place, resulting in linear or trapdoor fractures of the orbit. This transient buckling of the orbital walls tends to allow orbital soft tissue and extraocular muscle to herniate into the paranasal sinuses and become entrapped in the fracture region. ${ }^{15}$ In this series, which includes our own patient, five linear and two trapdoor fractures were diagnosed from the CT images.

Five of the seven patients were male. A male predominance in this age group is apparent and is a reflection of the aggressive risk-taking behavior of young boys. Injuries by falling are the most common cause of isolated orbital fractures in children younger than 5 years of age. In this series, six of the seven fractures were caused by falling. In young children, falling is an indicator for the diagnosis of a blowout fracture. However, because of the uncooperative attitudes of children of this age and the relative paucity of clinical signs (such as orbital hematoma and sub conjunctival hemorrhage), a physical examination performed in the emergency room setting is of limited value in the diagnosis of suspected blowout fractures. In cases where patients present symptoms including posttraumatic diplopia, periorbital swelling and/or nausea, vomiting, which may be caused by extraocular muscle entrapment, ${ }^{8}$ a CT examination of the orbit should be ordered.

When CT findings show a blowout fracture with extraocular muscle entrapment, as shown in case six, the early 
Table I The patient characteristics of young pediatric patients with blowout fractures of the orbital floor $(n=7)$

\begin{tabular}{|c|c|c|c|c|c|c|c|c|}
\hline Case & Age & Sex & Cause & $\begin{array}{l}\text { Fracture } \\
\text { site }\end{array}$ & $\begin{array}{l}\text { Fracture } \\
\text { type }\end{array}$ & $\begin{array}{l}\text { Muscle } \\
\text { entrapment }\end{array}$ & $\begin{array}{l}\text { Time to } \\
\text { operation }\end{array}$ & $\begin{array}{l}\text { Residual } \\
\text { diplopia }\end{array}$ \\
\hline I. Anderson and Poole' & $5 \mathrm{yr}$ & $\mathrm{F}$ & Falling & Lt floor & Linear & - & II weeks & + \\
\hline 2. Klenk and Kovacs ${ }^{2}$ & $\mathrm{I} y r$ & M & Falling & Lt floor & Linear & - & - & - \\
\hline 3. Klenk and Kovacs ${ }^{2}$ & $2 \mathrm{yr} 3 \mathrm{mth}$ & M & Falling & Lt floor & Linear & - & - & - \\
\hline 4. Ethunandan and Evans ${ }^{3}$ & $4 \mathrm{yr}$ & $M$ & Falling & Floor (site?) & Trapdoor & - & 5 days & - \\
\hline 5. Pluijmers et $\mathrm{al}^{4}$ & $3 \mathrm{yr} 10 \mathrm{mth}$ & $\mathrm{F}$ & Falling & Rt floor & Trapdoor & - & 27 days & - \\
\hline 6. Foulds et $\mathrm{al}^{5}$ & $5 \mathrm{yr}$ & M & Unknown & Rt floor & Linear & + & I day & - \\
\hline 7. Our case & $3 \mathrm{yr} 3 \mathrm{mth}$ & M & Falling & Lt floor & Linear & - & - & - \\
\hline
\end{tabular}

Notes: Cases I-6 were identified in a search of the PubMed database using the term "pediatric blowout fractures or blowout fractures in children".

Abbreviations: $y r$, year(s); mth, months; F, female; M, male; Rt, right; Lt, left.

exploration and release of entrapped muscle is recommended by many authors to avoid ischemic necrosis, fibrosis, and the scarring of entrapped muscles. ${ }^{1,3,8}$ Surgical intervention within the first day of the injury would seem to be the best treatment timing for the prevention of muscle fibrosis and has shown the best results. ${ }^{5,16,17}$ In pediatric patients, however, the entrapment of the extraocular muscle may be significantly underestimated by $\mathrm{CT}$ examination. ${ }^{18}$ Even if muscle entrapment is not indicated by $\mathrm{CT}$, persistent diplopia after the resolution of initial edema is a further indication for surgical intervention, as shown in cases one and four. ${ }^{3,4}$ On the other hand, Pluijmers et $\mathrm{al}^{4}$ reported one patient who required an operation due to late enophthalmos. In this case, a relatively wide trapdoor fracture might have been the cause of the late enophthalmos. In this age group, both the reestablishment of ocular movement and orbital volume are treatment goals.

In pediatric patients, the defects after entrapped orbital tissues are freed are often small; thus the reconstruction of the bone defects is not always necessary. ${ }^{7}$ Orbital floor reconstruction might, however, be necessary if the bone defects are wide after the freeing of the entrapped orbital tissues. A question remains as to what sort of material can be used for orbital floor reconstruction in early childhood. ${ }^{2,4}$ Nonresorbable plate and sheet-like materials could disturb the normal growth of the facial bones. Alloplastic materials have been provided in some cases, but have also failed to achieve their purpose due to infection or rejection. Some authors have suggested that thin but strong and resorbable artificial materials would be ideal for orbital floor reconstruction in early childhood (which involves a rapidly growing and changing facial skeleton), and that this could eliminate the need for a second operative site (for the harvesting of an autologous bone graft) and eliminate the risk of complications at the donor site. ${ }^{2,4}$ In this case series, pericranium, Vicryl ${ }^{\mathbb{R}}$ sheet, and Lyoplant ${ }^{\circledR}$ were used in the reconstruction of the orbital floor. ${ }^{1,3,4}$
While serious ocular or cerebral injuries and complications were not observed in any of the patients, complete ophthalmic and neurologic examinations are recommended in all cases when orbital blowout fractures are identified. ${ }^{19}$ To determine the gold standard of treatment for blowout fractures in early childhood, the careful long-term follow-up of pediatric patients is also required.

\section{Conclusion}

In the present case series, falling was the most common cause of the orbital floor fractures in early childhood. In cases where patients present symptoms including diplopia, periorbital swelling, nausea and/or vomiting after injuries, a CT examination of the orbit should be ordered for appropriate diagnosis and treatment immediately.

\section{Disclosure}

The authors declare no conflicts of interest.

\section{References}

1. Anderson PJ, Poole MD. Orbital fractures in young children. J Craniomaxillofac Surg. 1995;23(3):151-154.

2. Klenk G, Kovacs A. Blow-out fracture of the orbital floor in early childhood. J Craniofac Surg. 2003;14(5):666-671.

3. Ethunandan M, Evans BT. Linear trapdoor or "white-eye" blowout fracture of the orbit: not restricted to children. Br J Oral Maxillofac Surg. 2011;49(2):142-147.

4. Pluijmers BI, Koudstaal MJ, Paridaens D, van der Wal KG. Blowout fracture in a 3-year-old. Craniomaxillofac Trauma Reconstr. 2013;6(2): 133-136.

5. Foulds JS, Laverick S, MacEwen CJ. 'White-eyed' blowout fracture in children. Emerg Med J. 2013;30(10):836

6. Converse JM, Smith B, Obear MF, Wood-Smith A. Orbital blowout fractures: a ten-year survey. Plast Reconstr Surg. 1967;39(1):20-36.

7. Losee JE, Afifi A, Jiang S, et al. Pediatric orbital fractures: classification, management, and early follow-up. Plast Reconstr Surg. 2008;122(3): 886-897.

8. Bansagi ZC, Meyer DR. Internal orbital fractures in the pediatric age group: characterization and management. Ophthalmology. 2000;107(5): 829-836.

9. Carroll SC, Ng SG. Outcomes of orbital blowout fracture surgery in children and adolescents. Br J Ophthalmol. 2010;94(6):736-739. 
10. Posnick JC, Wells M, Pron GE. Pediatric facial fractures: evolving patterns of treatment. J Oral Maxillofac Surg. 1993;51(8):836-844.

11. Messinger A, Radkowski MA, Greenwald MJ, Pensler JM. Orbital roof fractures in the pediatric population. Plast Reconstr Surg. 1989;84(2): 213-216.

12. Koltai PJ, Amjad I, Meyer D, Feustel PJ. Orbital fractures in children. Arch Otolaryngol Head Neck Surg. 1995;121(12):1375-1379.

13. Sugamata A. Etiology of blowout fractures. The Journal of Tokyo Medical University. 2014;72(1):19-24.

14. Lane K, Penne RB, Bilyk JR. Evaluation and management of pediatric orbital fractures in a primary care setting. Orbit. 2007;26(3): 183-191.

15. Fujino T, Makino K. Entrapment mechanism and ocular injury in orbital blowout fracture. Plast Reconstr Surg. 1980;65(5):571-576.
16. Yano H, Minagawa T, Masuda K, Hirano A. Urgent rescue 'missing rectus' in blowout fracture. J Plast Reconstr Aesthet Surg. 2009;62(9): e301-e304.

17. Sugamata A, Yoshizawa N, Shimanaka K. Timing of operation for blowout fractures with extraocular muscle entrapment. J Plast Surg Hand Surg. 2013;47(6):454-457.

18. Parbhu KC, Galler KE, Li C, Mawn LA. Underestimation of soft tissue entrapment by computed tomography in orbital floor fractures in pediatric population. Ophthalmology. 2008;115(9):1620-1625.

19. Oppenheimer AJ, Monson LA, Buchman SR. Pediatric orbital fractures. Craniomaxillofac Trauma Reconstr. 2013;6(1):9-20.

\section{Publish your work in this journal}

The International Medical Case Reports Journal is an international, peer-reviewed open-access journal publishing original case reports from all medical specialties. Previously unpublished medical posters are also accepted relating to any area of clinical or preclinical science. Submissions should not normally exceed 2,000 words or
4 published pages including figures, diagrams and references. The manuscript management system is completely online and includes a very quick and fair peer-review system, which is all easy to use. Visit http://www.dovepress.com/testimonials.php to read real quotes from published authors.

Submit your manuscript here: http://www.dovepress.com/international-medical-case-reports-journal-journal 